
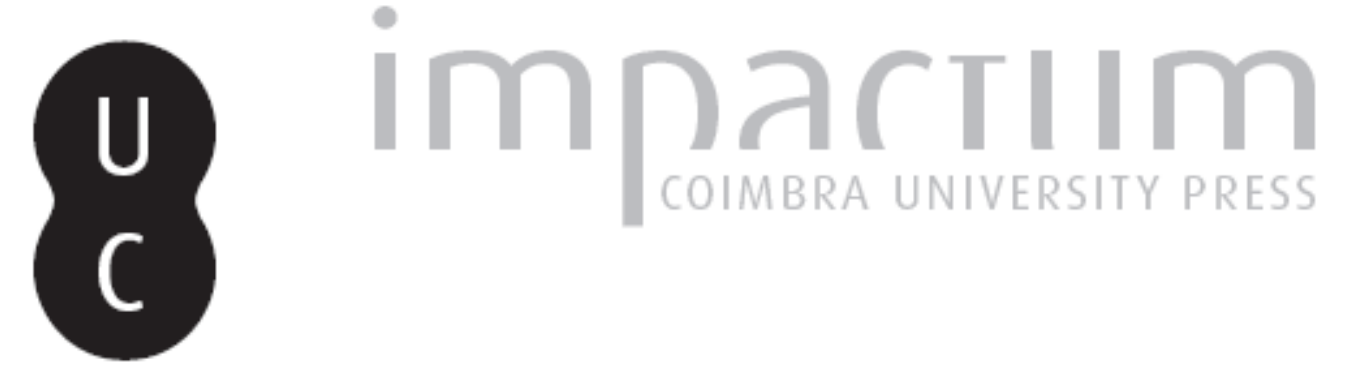

\title{
Comunicação do risco e gestão da ameaça pandémica
}

Autor(es): $\quad$ Almeida, Lúcio Meneses de

Publicado por: Associação Portuguesa de Riscos, Prevenção e Segurança

URL persistente:

URI:http://hdl.handle.net/10316.2/36229

DOI:

DOI:http://dx.doi.org/10.14195/1647-7723_14_9

Accessed : $\quad$ 26-Apr-2023 14:47:38

A navegação consulta e descarregamento dos títulos inseridos nas Bibliotecas Digitais UC Digitalis, UC Pombalina e UC Impactum, pressupõem a aceitação plena e sem reservas dos Termos e Condições de Uso destas Bibliotecas Digitais, disponíveis em https://digitalis.uc.pt/pt-pt/termos.

Conforme exposto nos referidos Termos e Condições de Uso, o descarregamento de títulos de acesso restrito requer uma licença válida de autorização devendo o utilizador aceder ao(s) documento(s) a partir de um endereço de IP da instituição detentora da supramencionada licença.

Ao utilizador é apenas permitido o descarregamento para uso pessoal, pelo que o emprego do(s) título(s) descarregado(s) para outro fim, designadamente comercial, carece de autorização do respetivo autor ou editor da obra.

Na medida em que todas as obras da UC Digitalis se encontram protegidas pelo Código do Direito de Autor e Direitos Conexos e demais legislação aplicável, toda a cópia, parcial ou total, deste documento, nos casos em que é legalmente admitida, deverá conter ou fazer-se acompanhar por este aviso.

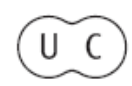




\section{territorium}




\section{COMUNICAÇÃO DO RISCO E GESTÃO DA AMEAÇA PANDÉMICA}

Lúcio Meneses de Almeida

lucioalmeida@arscentro.min-saude.pt Médico especialista em Saúde Pública

Serviças Regionais de Saúde Pública, ARS do Centro, Coimbra

\section{RESUMO}

A comnicação do risco é um processo interactivo de troca de informação sobre risco (natureza, gravidade e aceitabilidade) entre indivíduos, grupos e instituições relativo a situações que ameaçama saúde, a segurança a o ambiente. A comunicação do risco é um instrumento fundamental de gestão do risco quando inclui conselhos redutores do risco. A "gripe das aves", epizootia pelo vírus influenza A (HBNI) é um dos exemplos actuais da relevância dos commicadores do risco na gestão de uma ameaça. Cabe aos médicos de saúde pública peritos em commicação do risco promover a adequação do nível de consciencialização do público relativamente a este problema.

Palavras chave: Risco, comunicação do risco, infecção A (HБN1) , ameaça pandémica.

\section{ABSTRACT}

Risk com nication is an interactive process of exchange of information on risk (nature, severity andacceptability) among individuls, groups and institutions conceming issues that pose a threat to health, safety or enviroment. Risk commuication is a fundamental tool of risk management when it includes risk reduction advices. Avian influenza, an epizooty caused by HENI vinus, is a arrent example of the relevance of risk commicators in the management of a threat. Public health doctors, with an expertise on risk comminication, should act as promoters of an appropriate level of risk perception conceming avian influenza through the empowerment of the public.

Key words: Risk, risk commuication, vinus A (HEN1) infection, pandemic threat.

\section{RESUMÉ}

La commication du risque est un processus interactif de change d' information sur le risque (nature, sévérité et acceptabilité) entre les individus, les gropes et les institutions concemant les situations quemenace la santé, la séarrité ou l'environnement. Ia conmunication du risque est un autil fondamental de la gestion du risque quand elle inclue des conseilles sur la minimisation du risque. La grippe aviaire, épizootie causée par le vinus HEN, est un exemple actuel de 1 ' importance des comminicateurs du risque dans la gestion d'une menace. Les docteurs en santé publique experts en communication du risque doivent agir comme promoteurs de l' adéquation au niveau de la perception du risque de la grippe aviaire par le publique.

Mbts clé : Risque, comminication du risque, infection par le virus A (H5N1), menace pandémique. 


\section{Introdução}

Desde sempre que as epidemias assolaram a Humanidade, causando dbença, morte e incalculáveis prejuízos económicos. A peste negra da Idade Média ou a "gripe espanhola" ("pneumónica") do final da I Grande Guerra, são alguns dos exemplos de pandemias (epidemias à escala gldoal) que ceifaram milhões de vidas em todo o Mundo.

As primeiras pandemias de gripe documentadas ocorreram no século XVI: desde então o Mundo tem assistido a uma média de 3 pandemias por século, ocorrendo com intervalos entre 10 a 50 anos (WHO, 2005) . A mais mortal de todas terá sido a pandemia de 1918-19 em que estimativas recentes actualizaram a estimativa do excesso de óbitos em todo o Minndo de 20 a 40 mi lhões para 50 a 100 milhões (Johnson \& Mueller, 2002 citados por Osterholm, 2005) .

Em 1996 foi isolado num ganso doméstico na província de Guandong, na China, uma variante altamente patogénica (HPAIV - highly pathogenic avian influenza virus) de um vírus influenza A desconhecido até então: o vínus Hbill. Posteriormente, em 1997, são notificados na RAE de Hong Kong surtos em aves domésticas e as primeiros casas humanos de infecção por este vínus (WHO, 2006).

Apesar de não haver evidência epidemiológica ou laboratorial de transmissão inter-humana (pressuposto necessário para a emergência duma epidemia gldbal), este facto despertou preocupação por parte da comunidade científica intemacional, e em particular da Organização Mundial da Saúde, uma vez que se tratava dum vírus animal completamente novo (para o qual virtualmente toda a populaçãomundial é susceptível) e altamente vinulento - dos 18 casos humanos então identificados, predominantemente indivíduos jovens e previamente saudáveis, 6 faleceram em consequência da doença.

Em Janeiro de 2005, e face à evidência epidemiológica e laboratorial disponível, o então Director-Geral da OMS Dr. Lee Jong-wook alertava para a ameaça de uma pandemia de gripe: "During 2004, the world moved closer to a further pandemic than it has been any time since 1968", sendo a informação ao público e aos profissionais ( "informação e commicação em saúde pública" ) preconizada em todas as fases (WHO, 2005). Esta inclui a divulgação de informação sobre riscos e evicção do risco (risk avoidance) dirigida a populaçães-alvo (tai lored), incluindb a divulgação das medidas universais de higiene e de informação preparatória para as fases seguintes (WHO, 2005) .

Apesar do risco de infecção humana pelo vírus A (H5N1) ser, presentemente, muito baixo considerando que para uma população mundial de 6,5 mil mi lhões de pessoas, foram not ificadas desde
2003 cerca de 280 casas - e da via alimentar ser uma via de transmissão muito pouco provável ou mesmo teórica (ECDC, 2006) , a perceepcão do risco por parte do público traduziu-se nalguns países pela redução acentuada do consumo de produtos avícolas sempre que era noticiadb um surto aviário num país ou região mais ou menos distante e por níveis de ansiedade dissonantes do conhecimento científico disponível.

quando se verificaram os primeiros casos animais de infecção pelo vínus A (H5NI) na Erropa (Roménia) , verificaram-se quebras de consumo de produtos avícolas entre 40\% a 80\% em países como a Grécia ou Itália; em contrapartida no Reino Unido o consumo decresceu apenas 5\% quando da identificação dos primeiros casos em aves naquele país (Escócia) (Bioera, 2006).

O restaurar da confiança nas autoridades previamente abalada por crises de segurança al imentar como a encefalopatia espongiforme bovina (BSE) , mas que tiveram como consequência a criação de instituições govemamentais na área da segurança al imentar - terá contribuído para a estabi lidade do comportamento dos consumidores verificado no Reino Unido (Bio-era, 2006) .

O potencial pandémico de um qualquer novo vínus da gripe, como o vínus A(H5N1) , permite a const nução de cenários profundamente disnuptores, não dostante não ser possível prever a emergência da próxima pandemia de gripe, nem tão pouco qual o próximo vínus pandémico.

Os órgãos de comunicação social são instrumentos fundamentais de globalização da sociedade em todas as suas vertentes, incluindo na vertente da percepção do risco. Recentemente (Fevereiro de 2007) , um surto aviário em Inglaterra, numa unidade industrial de engorda de perus localizada emHlton (Suffolk) foi alvo de partialar atenção por parte da comunicação social em todo o Mundo tendo, inclusivamente, motivado o envio pelo Governo português do Autor, na qualidade de perito da Direcção-Geral da Saúde.

Essa missão de observação reforçou a convicção do Autor da imprescindibilidade de médicas de saúde pûblica, peritos em comunicação do risco, na gestão de ameaças à saúde humana potencialmente geradoras de alarme social.

O presente artigo faz uma breve caracterização do risco associado à presente panzootia ("pandemia" animal) pelo vínus A( $(\mathrm{H} 5 \mathrm{~N} \mathrm{l})$.

O autor destaca a comunicação do risco como instrumento fundamental de gestão da ameaça pandémica, traduzida pela divulgação de informação geral e sectorial compreensível, mas cientificamente fundamentada. 


\section{Gripe e suas implicações em saúde pửblica}

"La grippe se caractérise par sa rapidité d'extension. Fn 1918, elle a atteint l'Frropeen 6 semaines, la surface du globe en 6 mois. Ia saudaineté des explosions est précédáe de périodes prémonitoires penobant lesquel les quelques cas se déclarent. En fait, la grippe se propage de proche en proche, en fonction des commuications interhmaines. (...) Elle tauche les 2/3, les $4 / 5$ de la pquilation, sa léthalitéest variable"

Sédallian P, Sohier R. Précis d'hygiène et d'épidemiologie. Paris: Masson et Cie Éditeurs, 1949

"Pandemics are global in nature, lat their impact is local. When the next pandanic strikes, as it surely will, it is likely to tach the lives of every individal, family and cammity"

Michael O. Levitt, Secretary (US Department of Health and Human Services)

A gripe é uma doença respiratória aguda causada pelos vínus influenza (fanília orthomyxoviriobe) AeB. Apesar da seroprevalência da infecção pelo vínus C, este tem escassa relevância clínico-epidemiológica.

Os vínus influenza, vínus monocatenares de RNA, são genomicamente muito instáveis, pelo que se verificam todos os anos surtos de intensidade e gravidade variáveis, traduzidos por morbilidade significativa na pquulação geral (absentismo escolar e laboral) e mortalidade nos grupos com risco acrescido de complicaçães decorrentes da infecção gripal sazonal (caso dos idosos ou portadores de doenças crónicas) (Meneses de Almeida, 2006) .

A gripe sazonal afecta todos as anos afecta 100 milhões de pessoas no hemisfério Norte, sendo responsável por cerca de 1700 mortes no nosso País (Meneses de Almeida, 2006). Considerando a taxa de ataque bruta da gripe sazonal entre 5 a 10\% da população em geral, estima-se que todos os anos adoeçam entre 500000 a 1000000 de portugueses (Menteses de AIMEiDA, 2006).

A gravidade da infecção pelos vínus da gripe depende do grau de identidade antigénica relativamente aos vírus a que um indivíduo foi previamente exposto - seja por vacinação, seja por infecção natural. O anticonpo hemaglutinina (H) éo determinante mais importante de imunidade, uma vez que o antigénio $H$ facilita a adesão db vínus influenza aos receptores das células do hospedeiro (rinofaringe) .

No que diz respeito ao impacte da doença na commidade, este varia não só em função da memória imunológica relativamente ao vínus em questão, mas também do gnupo etário. Atendendo a que as crianças têm uma menor probabilidade de ter sido expostas aos vínus da gripe, a taxa de ataque (i.e., a proporção de afectados) para este grupo etário é substancialmente superior à dos adultos, além de desempenharem um papel "amplificador" da doença na commidade (albergam os vínus da gripe durante mais tempo das que os adultos - "shedding" de maior duraçãa) .

A gripe pandémica é provocada por vírus completamente novos (vínusA), para os quais não existe memória imunológica, afectando entre 25 a 30\% da população mundial. Nos últimos 300 anos terão ocorrido 10 pandemias: estima-se que a pandemia de 1918-19 ("pneumónica" ou "gripe espanhola") tenha sido uma das mais mortais, sendo-lhe imputadas 50 a 100 milhões de mortes em todo o Mundo (Osterholm, 2007).

O número de mortes relacionadas com uma qualquer epidemia depende da letalidade do agente infeccioso, da taxa de ataque da doença e da

Tabela 1 - Pandemias do século XX.

\begin{tabular}{|c|c|c|}
\hline ANO & SUBTIPO & GRAVIDADE \\
\hline $1889-90$ & H2N8 & Pandemia grave \\
\hline $1900-03$ & $\mathrm{H} 3 \mathrm{~N} 8$ & Epidemia moderada? \\
\hline $1918-19$ & $\mathrm{H} 1 \mathrm{~N} 1$ & Pandemia grave \\
\hline $1933-35$ & $\mathrm{H} 1 \mathrm{~N} 1$ & Epidemia moderada \\
\hline $1946-47$ & $\mathrm{H} 1 \mathrm{~N} 1$ & Epidemia moderada \\
\hline $1957-58$ & $\mathrm{H} 2 \mathrm{~N} 2$ & Pandemia grave \\
\hline $1968-69$ & $\mathrm{H} 3 \mathrm{~N} 2$ & Pandemia moderada \\
\hline $1977-78$ & $\mathrm{H} 1 \mathrm{~N} 1$ & Pandemia suave \\
\hline
\end{tabular}

(Adaptadode DolinR. Influenza. In: Fouci AS et al. (ecitors). Hamison's principles of intemal medicine, 14 thedition. New York: MbGraw Hilll, 1998)

população em risco (que no caso da gripe pandémica corresponde à população mundial uma vez que não existe, por definição, memória imunológica para os vínus pandémicos) .

Assim, mesmo que o próximo vírus pandémico venha a ter uma letalidade inferior à do vírus da pandemia de 1918 (estimada em 2 a 3\% - ECDC, 2007) , o simples facto da população mundial ser, na actualidade, mais de três vezes superior fará com que o impacte da próxima pandemia seja apreciável (OSTERHOIM, 2007) .

Não dbstante este facto, o impacte da próxima pandemia de gripe depende de vários "factores prognósticos" (positivos e negativos). Como factores prognósticos pasitivos, existe uma rede mundial de vigilância epidemiológica e laboratorial que permite identificar e gerir precocemente surtos e identificar alterações no genoma viral compatíveis com o aumento do potencial de transmissão inter-humana, 
bem como disseminar instantaneamente essa informação, sendo o estado do conhecimento médico e farmacológico incomensuravelmente superior ao do início do século XX.

No entanto, a maior prevalência de imunodeprimidos decorrente, nomeadamente, do envelhecimento global da população e da pandemia de HIV/SIDA, aliada à inequidade no acesso gldbal aos cuidados de saúde, são factores prognósticos negativos relativamente ao impacte (em termos de morbimortalidade) da próxima pandemia de gripe.

\section{Gripe zoonótica: a infecção humana pelo vírus A (H5N1)}

Em 1996 é isolado a partir dum ganso duma quinta na província de Guangolong, na China, uma estripe altamente patogénica do vírus A (H5N1) (WHO, 2006) . No ano seguinte, são notificados surtos em aves domésticas na Região Adiministrativa Especial de Hong Kong (WHO, 2006).

Nesse mesmo ano de 1997 ocorrem os primeiros casos de infecção pelo vírus A (H5N1) em humanos, também em Hong Kong, dos quais 6 foram fatais (WHO, 2005; WHO, 2006). O abate sanitário de milhões de aves - só em Hong Kong foram abatidas 1,5 mi lhões de aves em apenas três dias (WHO, 2005) - e a ausência de novos casos de dbença por este vínus aviário em humanos, fizeram com que a comunidade intemacional respirasse de alívio, face à aparente contenção do surto animal.

No entanto, em Fevereiro de 2003 são relatados em Hong Kong dois novos casos confirmados de doença pelo vínus A (H5N1) - um dos quais fatal - em dois fami liares com história recente de estadia na China Continental eum terceiro caso (fatal) damesma famúlia, não confirmado laboratorialmente (WHO, 2006) . Durante todo o ano de 2003 ocorrem surtos na Ásia, incluindo noutras espécies animais em cativeiro (felídeos) , e em Janeiro de 2004 são notificados à Organização Mundial da Saúde (OMS) novos casos de doença humana pelo vírus A (H5N1) em humanos no Vietname e na Tailândia (WHO, 2006) .

A avaliação do risco decorrente da emergência dum vírus da gripe completamente novo, ainda que não transmissível de pessca-a-pessca e da transmissão da infecção (por via zoonótica) ser pouco eficiente, resulta do facto de que cada nova infecção humana é uma nova oportunidade para o vínus mudar e adquirir características compatíveis comuma tranmissão interhumana eficiente e sustentada - seja por reconbinação genética (que pressupõe a co-infecção dum haspedeiro por vínus da gripe humano e aviário) seja por mutação adaptativa (processo sequencial de adaptação do vínus animal ao hospedeiro humano, com aumento do seu potencial de transmissão inter-humana) .

As semelhanças entre o vínus pandémico de 1918 (H1N1) e o vírus panzoótico H5Nl consistem na sua elevada virulência, no facto de afectar predominantemente indivíduos jovens e previamente saudáveis e de se manifestar clinicamente na forma de um síndrome de dificuldade respiratória grave decorrente de pneumonia viral primária (WHO, 2005) .

A evidência epidemiológica e laboratorial disponível permite concluir que a infecção humana pelo vírus H5N1 é, presentemente, adquirida por contacto próximo com aves infectadas (vivas ou

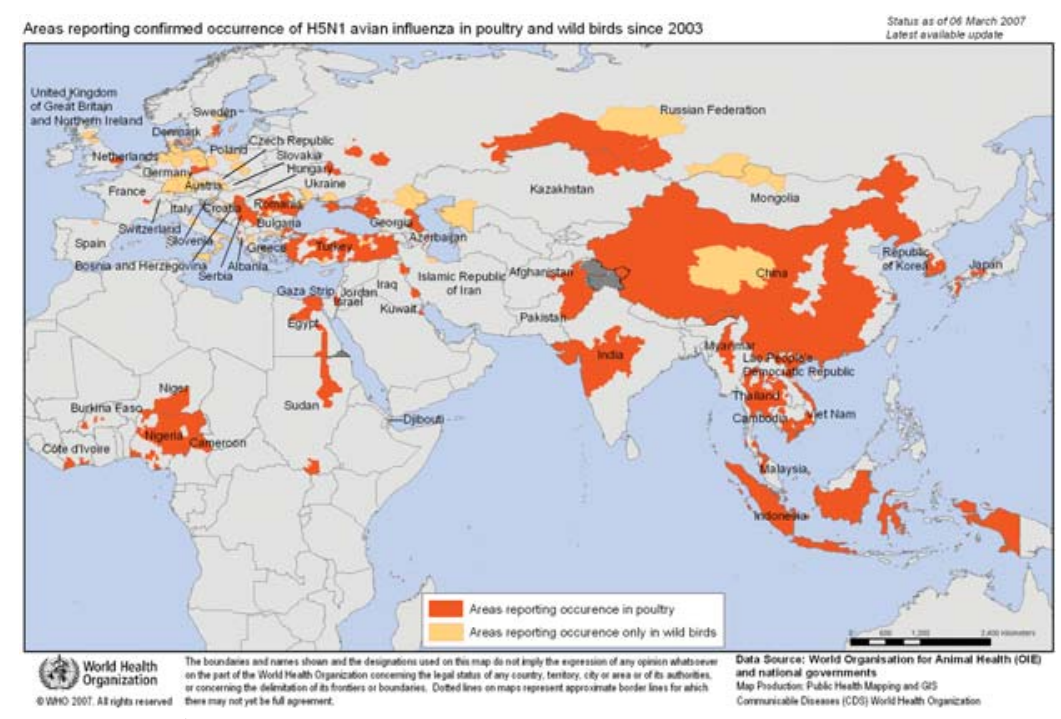

Fig. 1 - Áreas que notificaram casos confirmados de H5N1 em aves domésticas ou selvagens desde 2003 - situação reportada a 6 de Março de 2007 (WHO, 2007) . 


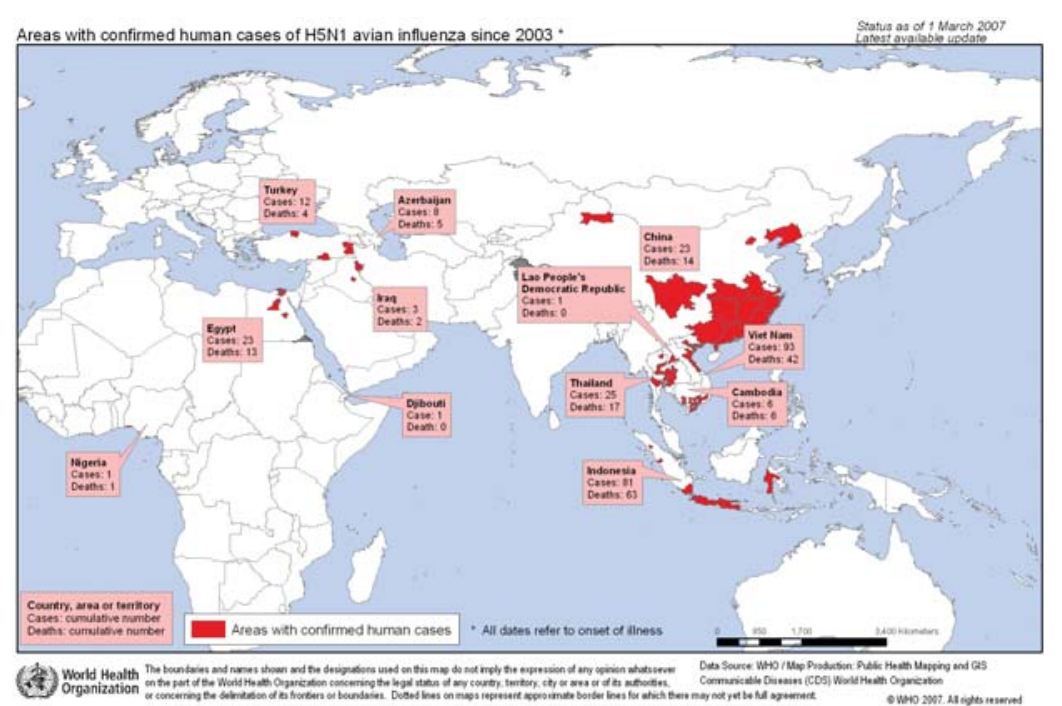

Figura 2 - Áreas afectadas que notificaram casos humanos confirmados de H5N1 desde 2003 - situação reportada a 1 de Março de 2007 (WHO, 2007).

Retiradb de http://gamapserver. who. int/maptibrary/Files/Maps/ Global_H5N1inHumanCUMULATIVE_FIMS_20070301.png (Acedido em 06/03/2007)

mortas) ou por contacto com seus produtos biológicos (nomeadamente fezes e secreções) - ainda que a eficiência da transmissão animal-homem da infecção seja muito baixa (ECDC, 2006), conforme se pode verificar pelo reduzido número de casos humanos notificadbs em todo o Mundo (Quadro I) .

Nb que diz respeito à via alimentar, considera-se que é uma via de infecção teoricamente possível, ainda que muito pouco provável (ECDC, 2006) . O adequado processamento térmico dos produtos avícolas permite anular o perigo associadb à exposiç̧ão al imentar, uma vez que o vírus HbN1 é, presentemente, destruído a temperaturas usuais de confecção de alimentos e não existe evidência epidemiológica de casos em humanos associados ao consumo de aves contaminadas quando confeccionadas a temperaturas compatíveis com uma temperatura no "múcleo" dos alimentos igual ou superior a $70^{\circ} \mathrm{C}$ (WHO, 20066) .

Quadro I - Número de casos humanos confirmados laboratorialmente de doença pelo vínus A (HENI) notificados à Organização Mundial de Saúde de 25/11/2003 a 01/ 03/2007 (datas de início de sintamas) .

\begin{tabular}{c|c|c|c|c|c|c|}
\hline & 2003 & 2004 & 2005 & 2006 & $2007^{*}$ & TOTAL \\
\hline $\begin{array}{c}\text { Casos } \\
\text { confirmados }\end{array}$ & 4 & 46 & 97 & 116 & 14 & 277 \\
$\begin{array}{c}\text { Mortes } \\
\text { relacionadas }\end{array}$ & 4 & 32 & 42 & 80 & 9 & 167 \\
\hline
\end{tabular}

* Até 1 de Março de 2007.

Fonte: WHO (2007) - Amulative number of confinmed human cases of avian influenza A/ (FBNI) reported to WHD. Disponível em http: //Www. Who. int/ csr/disease/avian_influenza/country/cases_table_2007_03_01/en/ print.hteml (acedido em 05/03/2007).
A evidência científica disponível no momento presente é compatível com a fase 3 do período de alerta pandémico da Organização Mundial da Saúde (Mbio de 2005) : casos esporádicas de infecção por novo sub-tipo de vínus em humanos, sem evidência de transmissão inter-pessoal ou, em casos raros, transmissão inter-pessoal limitada a contactos íntimos (WHO, 2005b) - ver tabela 2.

Em conclusão: presentemente, o risco de infecção pelos vínus aviários altamente patogénicos (HPAI) nos quais se inclui o vírus A/H5N1 - é "mínimo" (ECDC, 2006), mesmo nas regiões do Globo em que existemmíltiplas qportunidades de contacto com aves infectadas, como é o caso da maioria dos países asiáticos.

O nível mais elevadb de risco de infecção humana está associado à exposição a aves domésticas criadas a alojadas em quintais ou aviários domésticos que, por esse facto, não estão impedidas de contactar com aves migratórias (reservatório habitual dos vínus

Tabela 2 - Fases pandémicas: classificação da avs. (adaptado de WHO global influenza preparedness plan, WHO, 2005) .

\begin{tabular}{|c|c|c|}
\hline \multirow{2}{*}{ Periodo interpandémico } & Fase 1 & $\begin{array}{l}\text { Ausência de casos de infecção pelo vírus animal em } \\
\text { humanos; risco de infecção em humanos baixo }\end{array}$ \\
\hline & Fase 2 & $\begin{array}{l}\text { Ausència de casos de infecção pelo virus animal em } \\
\text { humanos; risco de infeç̧ăo em humanos substancial }\end{array}$ \\
\hline \multirow{3}{*}{$\begin{array}{l}\text { Periodo de alerto } \\
\text { pandémico }\end{array}$} & Fase 3 & $\begin{array}{l}\text { Casos de infecção pela estirpe animal em humanos mas } \\
\text { ausência de transmissāo interpessoal ou transmissão } \\
\text { limitada a contactos próximos }\end{array}$ \\
\hline & Fase 4 & $\begin{array}{l}\text { Pequenos clusters independentes e com limitada } \\
\text { capacidade de transmissão interpessoal (altamente } \\
\text { localizada) }\end{array}$ \\
\hline & Fase 5 & $\begin{array}{c}\text { Clusters de maiores dimensōes com capocidade de } \\
\text { transmissão interpessoal limitoda mas potencial } \\
\text { pandémico substancial }\end{array}$ \\
\hline Periodo pandémico & Fase 6 & $\begin{array}{l}\text { Transmissão (aumentada e sustentada) na populaçâo } \\
\text { em geral }\end{array}$ \\
\hline
\end{tabular}


influenza) (ECDC, 2006). É, precisamente, nas áreas nurais do Sudeste Asiático em que a infecção animal tem um carácter enzoótico, que o risco de infecção pelo vínus A (HEN1) é maior (WHO, 2005) .

Tal resulta do facto das medidas de controlo da infecção animal seremmais difíceis de implementar, não só porque as aves são elemento essencial da economia doméstica, mas também porque as várias espécies animais implicadas na filogénese dos vínus influenza convivem estreitamente entre si e com o Homem e porque os surtos são mais dificilmente detectáveis e controláveis do que em instalações industriais - além da inexistência de medidas de biossegurança nos aviários domésticos.

Na Europa - continente em que até à data não se verificaram casos humanos de gripe zoonótica pelo vínus A/HFII - e atendendo à segregação entre aves domésticas e humanos, o risco populacional é, na prática, limitado aos indivíduos envolvidos em actividades de controlo de surtos animais (caso dos trabal hadores de abate sanitário) e, eventualmente, aos residentes em áreas rurais que criam aves domésticas (emparticular mulheres) au que brincam comelas (crianças) (ECDC, 2006).

\section{Comunicação do risco e gestão da ameaça pandémica}

"(..) It is impossible to ignore the evident extreme confusion in the minds of the public between avian and pandemic influenza is striking. The perception of risk ismassive while (..) the actual risk to the individal fromavian influenza is incredibly low, even if they are exposed to infectedpaultry. Partially this is understandable since avian influenza can lead

anto pandemic influenza and the two issues are commonly tackled together in publications. However this is leading to disprqportionate anxiety and needs to be adkressed urgently."

(Interim ECDC risk assessment October 19th 2005 - updated

January 5th 2006: The public heal th risk from highly pathogenic avian influenza viruses emerging in Errope with specific reference to type $\mathrm{A} / \mathrm{HSN}$ )

"Commuication is of fundamental importance in the regulation of risks. It allons peqple to participate in, or be effectively represented in, decisions abat managing risks. An it plays a vital part in putting decisions into practice - whether helping people to understand regulations, informing them and advising themabat risks they can control themselves, or dissuading them from antisocial and risky behaviaur"

Dr. Jim McQuaid, Chairman (Intemational Liaison Group on Risk Assessment)
A commicação do risco (risk communication) "é um processo interactivo de troca de informação e qpiniões entre indivíduos, grupos e instituiçoes"s" (US Department of Health and Human Services, 2002) relativa a acontecimentos ou situações que ameaçam a saúde ou a segurança dos indivíduos ou das commidades.

A comunicação do risco é parte integrante do processo de análise do risco - que inclui a avaliação do risco (risk assessment) e a gestão do risco (risk management) (Meneses de Almeida, 2004). Apesar de independente da gestão do risco, a comunicação do risco assume-se como instnumento fundamental de gestão do risco em particular quando é veiculada informação relativa a atitudes ou comportamentos redutores do risco, além de contribuir para a prevenção ou controlo do alarme social associado (Mineses De AIMEIDA, 2006b) .

A gestão da ameaça pandémica na presente fase 3 do períodb de alerta pandémico, consiste em reduzir as oportunidades de exposição de humanos a animais infectados, primariamente através do controlo da doença animal e, secundariamente, através da prevenção de comportamentos associados à exposição inapropriada a animais potencialmente infectados (WHO, 2005C) .

A articulação com autros sectores da sociedade, emparticular o sector veterinário, e a divulgação de informação ao público em geral e a sub-grupos populacionais relativamente a medidas de prevenção e controlo da infecção de origem animal, são duas estratégias fundamentais na gestão db risco associadb à presente fase.

Apesar dos avanços significativos nos últimos dois anos relativos à preparação pandémica dos países da União Errropeia, o Centro Errropeu de Prevenção e Controlo de Doenças chamou recentemente a atenção para a necessidade da "expansão" dos planos de contingência do sector da saúde para autros sectores da sociedade (nomeadamente educação, actividades económicas, serviços sociais, etc.) - em concoroância com o mais do que certo impacte trans-sectorial duma pandemia de gripe (ECDC, 2007) .

A OMS advoga a comunicação transparente com o público no que diz respeito à progressão do surto animal e contingências a prever, bem como a parti tha de informação entre as autoridades de saúde e autros parceiros relevantes sobre "o que é conhecidb e o que não é conhecido" (WHO, 2005b) . Este último aspecto é da maior relevância, uma vez que a comunicação do risco inclui a comuicação da incerteza científica inerente a qualquer processo de tomada de decisão (i.e., degestãodbrisco) .

A identificação e difusão de mensagens-tipo (keymessages) , mediante o desenvolvimento de materiais 
de divulgação cientificamente fundamentados, actualizados e adequados aas vários públicas-alvo, são algumas das actividades a desenvolver pelos países tendo em vista a divulgação de informação relevante relativa à fase em questão e a preparação para a fase seguinte (WHO, 2005b; WHO, 2006; $E C D C, 2006)$.

A OMS, a FAO e a UNICEF identificaram quatro comportamentos prioritários redutores do risco de infecção animal e humana pelo vínus HbN1, a incluir em mensagens destinadas à população (WHO, FAO, UNICEF, 2006) :

* Nbtificar (report) às autoridades letalidade ou doença não usual de aves ou outros animais;

* Segregar (separate) aves domésticas de aves selvagens e de outros animais, bem como as efectivas recém-adquiridos das restantes animais, dissuadindo o contacto de humanos (emparticular crianças) com aves;

* Iavar (wash) cuidadosamente as mãos com água e sabão, após contacto com aves ou antes da manipulação de alimentos;

* Cozinhar (cook) adequadamente os alimentos, emparticular as prooutos avícolas (came de aves e ovos completamente cozinhados) .

Estas recomendações têm como público-alvo prioritário os países de menores rendimentos. Nestes países, os animais domésticos são parte fundamental da economia doméstica, pelo que eventuais surtos difici lmente serãonotificados às autoridades; por autro ladb, às deficientes condições higiossanitárias e ao contacto muito próximo entre animais e humanos aliase a inexistência de sistemas de vigilância epidemiológica e laboratorial efectivos.

Desta forma, e além da informação relativa a comportamentos redutores de risco, actualizada em função da evidência científica disponível, recomendase a abordagem de determinantes comportamentais culturais e socioeconómicos (por exemplo, indemizações compensatórias pelo abate sanitário de aves) tendo em vista promover a adesão às medidas preconizadas (WHO, FAO, UNICEF, 2006).

No caso específico da fase pandémica - a declarar pelo Director-Geral da OMS em função duma avaliação global do risco, independente da situação epidemiológica de cada país - caberá às autoridades nacionais manter o público e restantes "stakeholders" informados sobre a evolução da pandemia e preparar o público para a sua instalação no país, mediante a divulgação de medidas retardadoras da sua progressão.

Em Portugal, a Direcção-Geral da Saúde (uww.dgs.pt) criou no início de 2006 um microsite dedicado à gripe, contendo informação destinada aos profissionais (informação técnica) , aopúblicoe, pela especificidade deste gnupo etário, às crianças. Este último, sugestivamente intitulado "АTCHп: o lado divertido da gripe", pode ser acedido directamente através do endereço htttp: //gripeinfantil dogsaude.minsaude.pt/atchim/.

No microsite do Centro Regional de Saúde Pública do Centro, alojado na página web desta DirecçãoGeral, encontra-se igualmente disponível informação destinada ao público (em "Conhecer saúde" / "Gripe das aves" e em "Publicaçães" /"Desdobráveis") e aos profissionais de saúde (em "Material de apoio técnico" /"Gripipe") .

\section{Conclusões}

"Todos sabem que os efeitos de uma epidemia serão tanto menores quanto maior for a preparação cas respostas. (...) É a primeira vez que se antecipa um fenómeno desta escala. Sabe-se que a próxima pandemia de gripe tanto poole surgir dentro de seis meses como em seis anos. Se assimé, há que continuar em alerta, cando condições às sentinelas, mas sem alarme. Alerta sem alarme. Atentos. Informados. Confiantes."

Dr. Francisco George, Director-Geral da Saúde

Nunca, como na actualidade, Portugal e o Mundo se dedicaram, tão intensamente, à preparação para uma ameaça incerta mas real. Desde 2005 que a OMS vem alertando o Mundo para a necessidade de se preparar para uma ameaça decorrente do vínus aviário A(HBN1) face ao seu potencial pandémico. Este último resulta de três factores fundamentais:

a) Trata-se dum vírus completamente novo (virtualmente toỏ a população mundial é susceptível) ;

b) Terem decorrido mais de 35 anos após a última pandemia;

c) Carácter panzoótico da infecção - que condiciona uma maior probabilidade de exposição a animais infectados.

Considerando que cada novo caso de infecção humana aumenta o risco do vínus H5N1 poder adquirir características que possibi 7 itema transmissão interhumana eficiente e sustentada (fase 6 -pandemia) , a gestão do risco associado à presente fase 3 tem por dojectivo reduzir as oportunidades de exposição de humanos a aves infectadas.

A vigi lância laboratorial e epidemiológica temum papel "diagnóstico" duma eventual pandemia de gripe, a que se aliam, numa vertente "terapêtica", os planos de contingência de âmbito nacional (baseados nas orientações da OMS emanadas em 2005) .

A gestão da ameaça pandémica é a gestão da incerteza na mais pura acepção da palavra considerando que é impossível prever qual o próximo vírus pandémico e, como tal, qual o impacte da próxima pandemia (em termos de morbilidade, mortalidade e grau de disnupção sócio-econámico) . 
À semelhança dos acidentes rodoviários, só através duma "apólice de seguro" é que os países poderão minorar o impacte duma eventual pandemia, independentemente da sua imprevisibilidade.

Essa apólice de seguro corresponde à preparação dos países, qperacionalizada através dos seus planos de contingência para a pandemia de gripe, como o português. A finalidade dos planos nacionais de contingência é assegurar a resposta apropriada dos países a una eventual pandemia (fase 6), sem esquecer as restantes fases de actividade gripal (fases 1 a 5) .

No entanto, as planos de contingência de pouco valerão se o püblico não estiver devidamente informado e capacitado em termos de auto-prestação e procura apropriada de cuidados de saúde, facto que depende duma efectiva comunicação do risco durante as fases pré-pandémicas e fase pandémica.

Face à incerteza inerente à próxima pandemia de gripe, há que promover a capacitação da população sem, no entanto, desencadear opânico - i.e. , alertar sem alarmar. De facto, quanto mais bem informado estiver o público, mais facilmente compreenderá o risco, aderirá às recomendaçães das autoridades e terá um papel activo na gestão do risco (SAINAN \& LANARD, 2005).

No entanto, a comunicação inapropriada do risco mina a confiança e adesão do público às medidas preconizadas, comprometendo a efectividade das medidas de controlo (WHO, 2005d) .

Desta forma, a commicação do risco relacionado com ameaças à saúde das populações deve ser da responsabilidade de médicas de saúde pública cam competências específicas em avaliação e commicação do risco.

\section{Bibliografia}

BIO-ERA（BIO ECONOMIC RESEARCH ASSOCIATES) (2006) - "A bio-era teleconference: recent HBNI attbreaks: the evolving challenge of defining and commuicating pandemic risk". June 22, 2006. Bio Econamic Research Associates, IL.

EUROPEAN CENIRE FOR DISEASE PREVENTION AND CONIROL (2006) - Interim ECDC risk assessment October 19th 2005 (updated January 5th 2006) : The public heal th risk from highly pathogenic avian influenza viruses emerging in Errope with specific reference to type A/ H5N1.

EUROPEAN CENTRE FOR DISEASE PREVENTION AND CONTROL. INFLANAA TERM (2007) - "Pandemic preparedness in the Frropean Union: multi-sectoral planning needed"' . Frro Strveill, vol. 12(2):E070222.1. Protocolo disponivel em: http: //www.eurosurveillance.org/ew/2007/ 070222. asp\#1 (acedido em 01/04/2007).
Meneses de Aimeida, Lúcio (2004) - "Análise e commicação do risco em saúde pública: definiçães e conceitos". Anamesis, vol. 13, n 135, pp. 21-24.

Maners Ie Arvema, Lúcio (2006) - O papel dos serviças de saúde na gestão do risco pandémico [apresentação em ppt] . Protocolo disponível: microsite do centro Regional de Saúde Pública do Centro ("Material de apoio técnico") em http://www.dgs.pt [02 Março 2007] .

Menses te Armema, Lúcio (2006b) - "Ambiente, saúde e análise do risco ambiental: o exemplo da vigilância sanitária das praias fluviais". Territorium, vol. 13, pp. 53-58.

OSIFRHIM, M.T. (2005) - "Preparing for the next pandemic". New England Joumal of Medicine, vol. 352, n 18, pp. 1839-1842.

SANEANAN, Peter M. ; LANAPd, Jody (2005) - "Bird flu: commicating the risk". Perspectives in health, vol. 10, n० 2, pp. 2-9.

Wordd Healim Organizatian (2005) - Avian influenza: assessing the pandemic threat. WHO, s.l.

Wortd Heatth Organization (2005b) - WHO global influenza preparedness plan: the role of $\mathrm{WHO}$ and recommendations for national measures before and during pandemics. WHO, s.I.

Wortd Heatit Organizatton (2005c) - Responding to the avian influenza pandamic threat. WHO, s.I.

Wordd Healim Organizatton (2005d) - WHO outbreak comminication guidelines. WHO, s.l.

Wordd Health Organization (2006) - H5N1 avian influenza: timeline (8 May 2006) .

Wortd HEALTH ORGANIZATton (2006b) - Questions and answers on avian influenza: a selection of frequently asked questions on animals, food and hater (Exeative version) . WHO, Geneva.

Wordd Health Organizatton, fad, uncter (2006) - WHO/ FAO/UNICEF adhoc meeting on behavioural interventions for avian influenza risk redution: sumary and recormendations (14-16 March 2006) . WHO, Geneva.

US Departinent of Health and Human Services (2002) Commmicating in a crisis: risk commmication guidelines for public officials. Department of Health and Human Services, Washington, D.C. 